\title{
Summary and Prospect of Research on Technology Finance and Technology Innovation
}

\author{
Xinrui Yang* and Moyang Li \\ School of Economics and Management, Beijing Jiaotong University, P.R .China \\ ${ }^{*}$ Corresponding author. Email: mylee.bjtu@gmail.com
}

\begin{abstract}
On the basis of existing literature research, this paper analyses the two-way influence and mechanism of technology finance and technology innovation, and analyses the influence and mechanism of technology finance and technology innovation on regional economic development by studying the regional economic development in eastern, central and western regions of China. The results show that there will be positive feedback between technology finance and technology innovation, and technology finance will play a growth effect on regional economic development with the help of technology innovation; Enterprise innovation investment, government policy support and market financial resources all have a significant impact on the development of regional technology innovation, and their effects are different in different regions.
\end{abstract}

Keywords: Technological finance, Technological innovation, Regional innovation efficiency, International technological innovation.

\section{INTRODUCTION}

Technology finance is an financial environment system which aims to promote the development of science and technology, the transformation of achievements and the development of science and technology industry, takes government policies as the guide, takes banks as the leading factor, and takes multiparticipation and market operation as the key. By breaking the bottleneck of financial services in the growth period of science and technology enterprises, the financial environment system including organization, market, support and service is jointly constructed, which is the financing for science and technology innovation projects and science and technology start-ups. Under the new normal background, relying on the traditional extensive economic growth model at the expense of resource consumption is unsustainable. Promoting the development of knowledge-intensive industries through innovation and changing the traditional growth mode have become the key to achieve sustainable economic growth in China.

Based on this, scientific and technological innovation has become an important driving force to achieve high-quality economic growth under the new normal. Industrial structure transformation and healthy and stable economic development cannot be separated from scientific and technological innovation. However, innovation is a high-risk activity with high input, unstable output and uncertain return, so it cannot be separated from financial support. Only by leading financial innovation with science and technology, driving regional economic development with innovation, and giving full play to the development mechanism of effective integration of science and technology finance, can the driving force and supporting role of both in economic development be better realized. Since 2011, the central government has issued a number of technology and finance policy support documents, and the report of the 19th National Congress of the Communist Party of China identified the future development of the financial industry as enhancing the ability of financial services to the real economy.

In recent years, various provinces and cities across the country have actively carried out the construction of technological finance environment, and gradually formed their own distinctive technological finance development models in practice. However, due to the differences in regional economic development level and innovation ability, the development of technology 
finance shows different trends. The overall level, resources and environment, input scale and output capacity of technology finance in Beijing, Shanghai, Guangdong, Zhejiang and Jiangsu are relatively high; however, there are still many areas where the development level of technology finance lags behind, and the environmental construction in technology finance needs to be accelerated.

On the basis of existing literature research, this paper explores the two-way influence and mechanism of technology finance and technology innovation, and discusses the influence and mechanism of technology finance and technology innovation on regional economic development, in order to fully understand the strategic value of technology finance to China's economic development and provide advanced experience for promoting the coordinated development of regional economy.

\section{TWO-WAY INFLUENCE AND MECHANISM OF TECHNOLOGY FINANCE AND TECHNOLOGY INNOVATION}

As the first of the five development concepts in China, innovation plays an important role in optimizing resource allocation, improving labor productivity, and social and economic transformation. Scientific and technology innovation mainly exerts its dynamic mechanism in economic growth by promoting industrial transformation and upgrading, optimizing economic growth structure and improving total factor productivity. Zhang Yinyin et al. (2013) thought that technology innovation played an important driving role in the evolution from traditional industries to strategic emerging industries. Technology innovation can reduce input and consumption, improve the utilization efficiency of resources, and realize the growth of total factor productivity of technology innovation. Fan Jie et al. (2016) made an empirical study based on provincial layout data in China, which showed that the contribution of scientific and technological innovation to regional economic development has exceeded that of investment and export-oriented economy, and has become the key to the healthy development of national economy. In addition, the innovation achievements and technologies formed by scientific and technology innovation are shared and can be transferred from one production process to another without paying extra cost. With the increasing use of technology innovation achievements, the average innovation cost is decreasing, which is conducive to the formation of spatial agglomeration effect of technology innovation, and gradually evolves into the technological progress of the whole society.

China's demand for economic growth has gradually changed from factor-driven to innovation-driven, and technology and finance's investment is the embodiment of the concentration of capital factors in the field of innovation, and determines the development trend of scientific and technological innovation to a certain extent. On the one hand, the financial system can provide basic guarantee for $\mathrm{R} \& \mathrm{D}$ and production of high-tech products, and can promote high-tech $R \& D$ and industrial development. On the other hand, the financial system can spread the risks of technology innovation activities by combining different resources.

Foreign academic circles have done a lot of research on the influence of technology and finance on innovation activities. For example, King and Levine (1993) made an empirical analysis based on endogenous growth theory, and reached the conclusion that financial institutions can assess innovation risks through various paths, and then enhance the innovation ability of enterprises. Geoge and Prabhu (2003) think that development financial institutions can promote innovation more than commercial financial institutions. Weber and Weber (2007) further verified the above conclusions through empirical analysis, and the development financial institutions can have a significant positive impact on enterprise innovation. Sasidharan et al. (2014) conducted an empirical analysis based on Euler equation, and concluded that there is a significant positive correlation between $\mathrm{R} \& \mathrm{D}$ expenditure and corporate profitability and corporate financing amount. Po-Husan et al. (2014) studied the data of stock financing and credit financing in many countries, and came to the conclusion that external financing can significantly enhance the innovation capability of enterprises. The development of domestic commercial financial system is late, which makes the research on technology and finance started late by domestic scholars. Li Junxia et al. (2016) simulated and analysed the impact of technology and finance on high-tech industries based on system dynamics, and the results showed that market technology and finance played a more significant role in promoting high-tech industries. Shuitu Qian and Zhang Yu (2017), taking the data of Chinese listed companies as samples, empirically analysed the impact of technology and finance on R\&D investment of listed companies. The results show that technology and finance has a significant positive impact on $R \& D$ investment, so technology and finance can ease the financing constraints of listed companies, and this promotion is more significant in enterprises with high $\mathrm{R} \& \mathrm{D}$ investment.

In the system of technology innovation and technology finance, technology finance and technology innovation are closely integrated through the supplydemand relationship of funds. Technology finance promotes technology innovation in the form of funds, especially the market technology. And finance can effectively supervise its research and development and transformation of achievements while supporting technology innovation with funds, so as to guide the 
healthy development of technology innovation. On the premise of ensuring its own income, the market technological finance supports the capital demand of technological innovation with creditor's rights installment, equity transfer and loans; the technology innovation activities also give back the financial support of technological finance with the investment income brought by the effective transformation of innovation achievements. The specific role of government-oriented policy technology finance in technology and finance subsystem is reflected in guiding funds to choose capital investment according to the specific differences of scientific and technology innovation projects. And with tax incentives, promoting cooperation between banks and enterprises, realizing investment and loan linkage and other policy support, it helps science and technology enterprises to reduce the multiple pressures of insufficient funds in the process of innovation and development.

Policy technology finance and market technology finance support technology innovation based on a certain benefit return, and the continuity of return depends on the long-term interaction between the two subsystems. Government-oriented policy technology and finance obtains social benefits in the form of corporate taxation, accelerates the flow of knowledge, and realizes scientific and technological innovation mainly advocated by the government. The market technology and finance is to realize the return on investment of science and technology enterprises by obtaining capital gains or interest. Giving full play to the capital allocation capacity of technology and finance can increase the production capacity and scale of technology innovation, and then improve the investment efficiency of technology and finance. The improvement of investment efficiency in technology and finance will further promote the increase of scientific and technological capital investment and the improvement of scientific and technological innovation efficiency. There will be positive feedback in the process of collaboration between technology finance and technology innovation, and positive feedback is the best result of collaboration between technology finance and technology innovation.

However, in different stages of the development of technological enterprises, different technology and finance tools have different functions. Government policy finance can help technological enterprises overcome the problem of insufficient funds in R\&D activities in the early stage of their development. Generally, it is supported by the government through the policy inclination and financial input of public technology and finance to reduce the risks of science and technology enterprises in the initial stage, so as to promote the active development of science and technology innovation activities and the steady growth of knowledge economy. On the other hand, the market technology and finance subjects tend to invest in innovative projects with high potential value, and promote the efficient transformation and industrialization of innovative achievements by means of prior assessment and process supervision, so as to obtain high returns. At the same time, the promotion of innovation achievements can attract more capital agglomeration, and promote the expansion of technology and finance's scale, more active technology innovation activities and higher technology innovation output. On the contrary, if the technology innovation activities are not supported by enough technology and finance, the development of scientific and technological activities, the transformation of innovation achievements and the industrialization process can not be carried out smoothly, which weakens the activity of innovation activities, further affects the investment income and enthusiasm of technology and finance, and finally inhibits the steady development of knowledge economy.

\section{THE IMPACT OF TECHNOLOGY FINANCE AND TECHNOLOGY INNOVATION ON REGIONAL ECONOMIC DEVELOPMENT AND ITS MECHANISM}

At present, there are obvious differences in economic development among the eastern, central and western regions of China. Chen Peiyang et al. (2012) analysed the regional economic differences in China based on different research measures and found that since 1998, the regional economic development differences in China have shown an expanding trend. There are also great differences in the degree of closeness between technology and finance, technological innovation and economic development in different regions. Some provinces make strategic arrangements for capital chain, industrial chain and innovation chain, increase capital investment in technological innovation, smooth the transformation channels from basic research to applied research, and promote the economic growth effect of technological development; However, some provinces cannot effectively match the relationship between scientific and technological development and economic needs, resulting in insufficient integration between the two.

When studying the influence of technology and finance on regional economic development, this paper finds that some scholars focus on the analysis of the influence of technology and finance on the regional innovation efficiency of China's high-tech industries. A large number of scholars' researches show that the innovation efficiency of high-tech industries varies greatly from place to place. Yu Yongze (2010) divided the technological innovation process of high-tech industries into two stages: technological development 
and transformation of technological achievements, and found that the innovation efficiency of a large part of high-tech industries in China's provinces is very low, and the efficiency value of each stage can be improved through efforts, and the innovation efficiency of municipalities directly under the Central Government with developed high-tech industries and Guangdong region has been at a high level. After analysing the panel data of 30 provinces and cities in 2009-2010, Liu Wei and Li Xingxing (2013) found that the efficiency of technological innovation in high-tech industries in different provinces and cities in China was significantly different, with the eastern region being higher than the western region and the western region being higher than the central region. The three regions generally have large scale efficiency, while the pure technical efficiency is relatively small. Some scholars also focus on the empirical research on the impact of technology and finance investment on manufacturing innovation efficiency. Guo Yanqing and Haiming Li (2019) used deap software to calculate the innovation efficiency of China's overall and regional manufacturing industry, and found that the innovation efficiency of manufacturing industry in different regions of China is not completely the same. Among them, the manufacturing innovation efficiency in eastern China is the highest, followed by western China, and the manufacturing innovation efficiency in central China is the lowest.

The eastern coastal area is the earliest area of China's reform and opening up, and it is also the area with the deepest reform and opening up and the most developed economy. The development level of technology and finance and scientific and technological innovation is relatively high, and the venture capital operation is also relatively standardized. technology and finance has a strong role in promoting scientific and technological innovation; On the whole, the innovation efficiency of high-tech industries and manufacturing industries in the western region is higher than that in the central region, which is mainly due to the continuous deepening of the western development planning and the continuous promotion of the "the belt and road initiative" initiative. Under the guidance of policies, the western region has obtained more preferential policies and financial support, won the favor of capital and technology, and greatly improved its innovation efficiency. The central region has the lowest innovation efficiency. The reason may be that there is a big gap between the technical level of the central region and the eastern region, and the utilization rate of innovation investment funds is relatively low. Compared with the western region, the central region lacks sufficient policy support, which makes it difficult for the central region to form an agglomeration effect on talents and funds, and the innovation efficiency is relatively low.
Technology finance is the financial support and guarantee to carry out technology innovation, which is the driving force and core engine to promote economic growth. It can be seen from the above that technology and finance does not directly promote economic growth, but exerts its economic growth effect through the transmission path of "technology and finance-scientific and technological innovation-regional economic development". In my research, I found that no matter from the perspective of regional high-tech industry innovation efficiency or from the perspective of regional manufacturing innovation efficiency to study the mechanism of technology and finance's role in regional economic development, the three elements of enterprise innovation investment, government innovation support and market financial resources can have a significant impact on the development of regional scientific and technological innovation.

\subsection{Enterprise Innovation Investment}

Enterprises are the concrete implementers of technology innovation and the main body of scientific and technological innovation activities. Compared with other innovation subjects, enterprises have a clearer understanding of the development direction of science and technology and the latest market trends, and at the same time have more market supply and demand information. Therefore, enterprises will carry out relevant scientific and technological innovations in a targeted manner, and their related investment can enhance the innovation efficiency of manufacturing industry. However, in areas with low innovation efficiency, because most of the technological innovation enterprises are small start-up enterprises with low internal management level, the energy of enterprises is mainly focused on the development of product markets. Facing the vast financial market and complex and changeable financial products, it is difficult to have enough time to deeply understand and choose financial institutions that can meet their own financing needs at low interest rates. In addition, the information barriers between technological enterprises and financial institutions lead to insufficient investment and too many pseudo-innovations, which makes it difficult to really improve the efficiency of technological innovation.

\subsection{Government Innovation Support}

At the national level, the government's support for innovation is less significant. It may be that many local governments lack a scientific evaluation system for innovation investment, which leads to the mismatch of resources in government investment. The western region has received increasing investment and improved management with the support of the government. For the eastern and central regions, too much government investment leads to crowding-out effect greater than 
promoting effect, and the government often pays more attention to short-term benefits while ignoring long-term benefits. The lack of government investment has limited impact on innovation efficiency.

\subsection{Market Financial Resources}

In China's existing financing system, indirect financing led by commercial banks is still the most important financing method. However, with the continuous improvement of China's capital market and the continuous advancement of technology and finance, the development of venture capital, bonds, stock market and science and technology credit has a greater impact on China's scientific and technological progress. Because venture capital firms are very strict in screening investment target enterprises, the eastern region is easy to get financial support from venture capital firms because of their high innovation ability and management level, while the western region is easy to get financing from venture capital firms because of a large number of policies and government financial support. Venture capital companies can not only bring capital to enterprises, but also improve their management ability by participating in the management of innovative projects, thus promoting the efficiency of technological innovation. For start-up enterprises that are difficult to obtain venture capital, bank credit provides them with a large amount of funds. Through the scientific and technological credit of commercial banks, the shortage of funds in innovation can be alleviated to a certain extent, and then the innovation efficiency can be significantly promoted.

In view of the different development degree of science and technology innovation in different regions, there are obvious differences in the coupling coordination degree between technology finance system and technology innovation system in different regions. Jiehonglan establishes the efficacy function and constructs the coupling coordination degree model of technology finance and technology innovation. Combined with the spatial statistical method, through ArcGIS 10.2 software, the overall coupling coordination degree has a gradient change trend in space and decreases from coastal to inland. On the whole, the coordinated development of technology finance and technology innovation presents a spatial pattern of "high in the east and low in the west, high in the south and low in the north". The degree of system coupling and coordination in the eastern region with relatively developed economy is generally higher than that in the northeast, central and western regions with low economic development level. This is closely related to the local technology and finance resources and the government's macro-policy inclination. The eastern coastal areas have obvious advantages in teaching the central, western and northeastern regions in terms of technological financial resources and technological human resources. Not only are there many institutions in technology and finance, but the government has a strong guiding role in technology and finance's industrial policy, and both tend to develop well. However, for a long time in the low-level coupling and coordinated development stage, technology finance is relatively short of capital and scientific and technological innovation output, and the two have not yet formed a benign interactive coupling development model, so there is still much room for improvement in its coupling and coordinated development.

\section{CONCLUSION AND PROSPECT}

\subsection{Conclusion}

This paper combs the existing research on technology finance and technology innovation at home and abroad, and draws the following conclusions:

(1) Technology innovation has become an important driving force to achieve high-quality economic growth under the new normal. Technology innovation mainly exerts its dynamic mechanism in economic growth by promoting industrial transformation and upgrading, optimizing economic growth structure and improving total factor productivity. However, due to the characteristics of high investment and uncertain risks, technology innovation needs financial support. While supporting technology innovation activities, finance will also receive investment income feedback brought by the effective transformation of innovation achievements. There will be positive feedback in the collaborative process between technology finance and technology innovation, which will play a significant role in promoting economic development.

(2) Technology finance does not directly promote economic growth, but exerts its economic growth effect through the transmission path of "technology and finance-scientific and technological innovation-regional economic development". There are obvious differences in economic development among the eastern, central and western regions of China, among which the eastern region has the highest efficiency of technology innovation, followed by the western region and the central region has the lowest efficiency of innovation. This is closely related to technology finance factors such as enterprise innovation investment, government innovation support, market financial resources, etc., and its impact efficiency is also different for different regions. The eastern region has a higher level of economic development and the independent development of enterprises is in a leading position, while the western region is more dependent on government support and develops slowly. For the eastern region with high innovation level and 
management ability and the western region with a large amount of government support, it is easier to get financial support from venture capital firms, while the relatively weak central region can alleviate the shortage of funds in the initial stage of enterprises to a certain extent through direct financing such as science and technology credit.

\subsection{Prospect}

Based on the above research conclusions, this paper holds that although technology finance has an obvious positive influence on the efficiency of China's technology innovation, and the two promote the rapid development of China's regional economy in the process of mutual synergy and coupling, in order to give full play to the maximum role of technology finance, we should also fully consider the different natural basis, location advantages, historical background and policy conditions of different regions, and carry out the coordinated development of differentiated regional technology finance and technology innovation.

(1) In the case of low efficiency of regional innovation, the government should play a backbone role and increase guidance and support for technology innovation. Appropriately increase financial support for science and technology, encourage enterprises to increase $\mathrm{R} \& \mathrm{D}$ investment through tax and other preferential policies, and strengthen confidence for venture capital to support regional innovation and development. In addition, while increasing innovation support, we should also pay attention to the support effect to ensure that government finance is used in the cutting edge.

(2) In areas where the efficiency of regional innovation is steadily increasing, independent innovation of enterprises should gradually shoulder heavy responsibilities, create new products and markets through high-quality scientific and technological research and development, pay attention to early incubation, carry out public relations of original cuttingedge technologies, and stimulate the vitality of the enterprise market. Actively establish a sharing platform for financial service science and technology information, in which science and technology enterprises can publish relevant financing demand information. By pushing the information to the clients of relevant financial institutions, the sharing platform can effectively reduce the information asymmetry between technology and finance institutions and science and technology innovation enterprises.

(3) For areas with relatively high regional innovation efficiency, we should not rely too much on government support, nor allow enterprises to invest independently. We should actively build a comprehensive platform combining technology and finance with scientific and technological innovation, actively play the coordinating role of relevant departments, and jointly build a regional technology and finance collaborative innovation support platform with Chinese characteristics to create an environment for the development of SMEs.

In the future, China should continue to optimize the structure of financial resources, strengthen the marketoriented reform of the financial system, innovate the new mode of equity pledge financing, vigorously promote the reform and development of the stock public offering market and corporate bond market, let highquality enterprises and overseas $M \& A$ projects raise funds through direct financing, and give full play to the high efficiency of capital market in resource allocation.

\section{REFERENCES}

[1] [1]. Qiu Zhaoxiang. Promoting the combination of science and technology and finance to boost China's economic transformation [J]. Theoretical Exploration, 2015(03):5-9.

[2]. Zhang Yinyin, Deng Ling. Innovation drives the transformation and upgrading of traditional industries to strategic emerging industries: mechanism and path $[\mathrm{J}]$. Economic System Reform, 2013(05):97-101.

[3]. Fan Jie, Liu Hanchu. The influence and adaptation of the driving force of scientific and technological innovation on the change of regional development pattern in China during the 13th Five-Year Plan period [J]. Economic Geography, 2016,36(01):1-9.

[4]. obert G. King, Ross Levine. Finance and Growth: Schumpeter Might Be Right[J]. The Quarterly Journal of Economics, 1993.

[5]. Gerard, George, and, et al. Developmental financial institutions as technology policy instruments: implications for innovation and entrepreneurship in emerging economies[J]. Research Policy, 2003.

[6]. Weber B , Weber C . Corporate venture capital as a means of radical innovation: Relational fit, social capital, and knowledge transfer[J]. Journal of Engineering and Technology Management, 2007, 24(1-2):11-35.

[7]. Subash Sasidharan, P.J. Jijo Lukose, Surenderrao Komera. Financing constraints and investments in R\&D: Evidence from Indian manufacturing firms[J]. The Quarterly Review of Economics and Finance, 2015, 55(feb.):28-39.

[8]. Hsu P H, Tian X, Xu Y. Financial development and innovation: Cross-country evidence [J]. Journal of Financial Economics, 2014. 
[9]. Li Junxia, Zhang Zhe, Wen Xiaoni. An Empirical Study on technology and finance's Support for the Development of High-tech Industry — Based on System Dynamics Method [J]. China Management Science, 2016,24(S1):751-757.
[10].Shuitu Qian, Zhang Yu. Research on the Influence of technology and finance Development on R\&D Investment of Enterprises [J]. Scientific Research, 2017, 35(09):1320-1325. 